\title{
Stress and its Triggers of Early Adolescents - Institution and Gender Specific Differences
}

\author{
Maraichelvi AK \\ Department of Human Development, Avinashilingam Institute for Home Science and Higher Education for Women, India
}

Copyright (C) 2015 Horizon Research Publishing All rights reserved.

\begin{abstract}
Early adolescence in their middle school are said to pass through a tumultuous developmental period and are considered to be more vulnerable to stress. The present study was undertaken with the objective of appraising the stress level and stress triggers of middle school students and analyse the institution and gender specific differences. The study adopted survey research by formulating a situationbased checklist. Boys responding to the survey reported higher mean score on stress and that the students enrolled in government schools were more stressed than private school students. Also it was observed that except for the trigger teacher, all other riggers has got a significant interaction effect between the type of the school and gender of the selected adolescents. The overall finding gives a feeling of apprehension for the society in general and educators, researchers and policy makers in particular to initiate urgent strategies to overcome this fiery issue.
\end{abstract}

Keywords Early Adolescence, Stress Triggers, Institution-specific, Gender Specific Differences

\section{Introduction}

The adolescent years are among the most stressful times in a person's life. The formula 'no longer a child-not yet an adult' vividly expresses the transitional character of adolescent life. It is a state in which the person has already broken with the happy age of childhood, but has not yet found himself in adult life. That is why adolescent's mind is confused. The age of adolescence is marked by psychological manifestations that have caused it to be described as 'an age of crisis and transition'. This verdict is very true with the early adolescents. Early adolescence is considered as a tumultuous developmental period due to the rapid psychological, social and physical changes that the adolescents experience as they go through puberty and increase independent living skills [1,2].

The changes that occur in adolescence occur within almost every domain of the student's life - physical, social, educational and familial. Most of these changes are gradual and have different timetables and magnitudes for different adolescents. However, one change that has a predictable timetable for the entire peer group is the educational move into middle school. This change brings with it increased academic demands and social challenges that can lead to stress and adjustment problems for some adolescents $(3 ; 4)$.

The pre-existing difficulties pertinent to this age may be compounded in middle school because, in comparison to elementary school, middle school generally means a more complex learning environment. The complexity of the new learning environment with recent changes in school curriculum, constructivist approach in instruction, modern trends in a rapidly growing competitive society increases both academically, in terms of grading practices and the amount of material that the student must organize and master, and socially, in terms of negotiating larger and more fluctuating peer groups and more conflictual student teacher relationship [3]. Further, these difficulties related to academics and peers, are likely to become more stressful as students seek to develop greater autonomy, more intimate peer relationships, and a sense of identity.

Students are put in a position of feeling that they just must not stop. They are not given a sense of support. They are put in an environment where they are not accepted for themselves but only for what they are going to achieve. All this builds stress [5]. Every year, more and more pressures regarding classes, getting into the right courses, families, jobs, extracurricular activities, friends, relationships and other stimuli just keep burbling away beneath their still-developing forms. Suffice it to say, this avalanche of stress hinders their progress and personalities far more than it helps. Without persistently striving towards an unattainable perfection, students find themselves trapped between success and failure, with no 'gray areas' in between. And the situation worsens every year.

There can be a variety of causes for stress among students. Things that cause stress are called stressors [6]. There are inside and outside factors that could easily cause stress and it depends on each individual how this stressor would affect his life. Internal sources of stress include hunger, pain, 
sensitivity to noise, temperature change, crowding (social density), fatigue, over and under stimulation from one's immediate physical environment.

External stressors include separation from family, changes in family composition, exposure to arguing and interpersonal conflict, exposure to violence, experiencing the aggression of others (bullying), exposure to excessive expectations for accomplishment, 'hurrying' and disorganization in one's daily life events [7]. Stress from school workload and the student's inability to manage all his work in his allotted time could all lead to stressful student life. Even financial difficulties and family problems could get in the way of positive thinking. Stressed out and negligent parents, high expectations in academic or other performances, abused or deprived childhood, growing up tensions and demand for familial responsibility are the main causes of childhood and teen stress $[8 ; 9 ; 10]$.

\section{Theoretical framework}

If any age group has a reputation of having problems and causing trouble, it is the stage of adolescence. This is supposedly the time when angelic children are transformed into emotionally unstable, unruly and problem ridden delinquents [11]. The dominant theme of early adolescence, approximately ages $12-14$, is the individuals response to changes in sex hormone levels and a general growth spurt [12]

G.Stanley Hall, a monumental figure in the field of child and adolescent development, described adolescence as suggestive of some ancient period of 'storm and stress.' Hall's recapitulation theory of human development predicted storm and stress to be the norm of adolescence, rather than an exception, because each individual has to go through the major evolutionary stages, with the period of adolescence recapitulating the time from savagery to civilization. Adolescents have to experience pubertal changes and juggle myriad tasks to overcome chaos and become stable, responsible adults. This process of breaking the old moorings to attain higher levels will inevitably incur storm and stress. However, the sky will clear up after the storm is over -for most adolescents, the outcome is optimistic. The adolescent stress, that too proving to be tumultuous in the early stage i.e., early adolescence, served to be the rationale of why the students of $6^{\text {th }}, 7^{\text {th }}$ and $8^{\text {th }}$ standard are being focussed in the present research.

\section{Rationale of the study}

Early intervention assumes importance in addressing chronic stress symptoms and the studies need to be targeted at a group where corrective measures can bring about an impact. The period of early adolescence or the middle school age group is considered to be most vulnerable to stress, as these group of children are in the transition stage and has become the ideal target group for such studies. Therefore students of $6^{\text {th }}, 7^{\text {th }}$ and $8^{\text {th }}$ standard from both private and government schools were considered for the study as they are to step into the high school having gung ho public exams.
Also several studies have come up with different results of the stress levels among private and government school. The present study wanted to verify the marked difference level in the stress level of the children enrolled in private and government school and also analyse the various triggers related to stress.

\section{General objective}

With this background the present study was undertaken with the objective of appraising the stress level and stress triggers of early adolescents and analyse the interaction effect between institution (type of school the adolescents are enrolled into - private and government) and gender specific differences.

\section{Hypothesis}

- Institution and gender specific differences do not have any effect on the stress level of early adolescents.

- Institution and gender specific differences do not have any effect on the stress triggers of early adolescents.

\section{Materials and Methods}

The study adopted Survey research to assess the level of stress and its triggers among the early adolescents.

\section{A. Population and sampling}

Coimbatore was identified as the locale for the present study as it is one of the fastest growing tier-II cities in the state of Tamilnadu, India and a major textile, industrial, commercial, educational, information technology, healthcare and manufacturing hub of Tamil Nadu attributing to both parents working culture of Coimbatoreans. Also by considering the likelihood of generalizing the results, multistage sampling procedure was adopted for the present study and the sampling process was carried out in two stages namely

\section{i. Selection of schools}

Twelve schools (both private and government) in and around Coimbatore were shortlisted from the four zones - 3 schools in each zone (12 schools in total). The study set norms for identifying and selecting schools in order to ensure homogeneity between the participant schools, namely the type of syllabi offered (Samacheer Pattern), distance (5-15 Kilometres) and the type of school (Higher Secondary School).

Consequently, out of the 12 schools, six schools extended their willingness to be a part of the research. Hence all these six schools were selected for the data collection which comprised of three private and three government schools distributed among the four zones of Coimbatore.

\section{Selection of the sample}

Purposive sampling technique was used to select respondents from the identified six schools for administering the constructed tools among the student population in their 
6th, 7th and 8th standard. Therefore a sample of school students (Private S1 - 1227 and Government S2 - 590) comprised the population sample.

\section{Ethical Consideration}

As a matter of ethics the student respondents were informed about the research orally and a written consent form was obtained from their parents. The sample was thus allowed to make a voluntary choice for participating. The present study was also subjected to Institutional Human Ethical Committee and was approved for the same (Appr No. - AUW/IHEC -13-14/XMT-51).

\section{B. Tools used}

An appropriate situation based checklist was developed after reviewing the literature and consulting the experts. The check list was carefully formulated in such a way that it gives two important measures relevant to the study pursued.

\section{a) Stress level of the middle school students}

This checklist had a total of 75 items. The mode of response to each of the item was in the form of a forced choice (i.e.) either 'yes' or 'no', indicating complete agreement or disagreement with the proposed statement. For scoring, one mark to be provided for the response indicating the presence of stress and zero for its absence. The checklist gives the total stress score based on which the levels of stress in children were divided into low (0-25), moderate (26-50), and high (51-75).

\section{b) The stress triggers of these students}

By thorough review of literature and informal chat of the investigator with the parents, teachers and the students identified for the study, seven stress triggers were recognized in common. They were teacher, money, attitude and feelings, school work, exam, parents and friends.

The above said checklist was formed in such a way that the response identifies the stress inducing factors that were being perceived as stressors by the selected students. The total of 75 items was distributed among the identified seven stress triggers. The scores were summed up for each stressor and subjected to analysis in order to find out the order of prominence of the factors associated with the increased stress level of the selected school children.

\section{Tool standardization}

\section{Validation}

The framed statements of the tool for students were scrutinized to look at the operationalization and to check whether 'on its face'. The statements appeared to measure the level of stress and identify the stressors. This tool was also subjected to content validation.

\section{Pilot study}

The tool after content validation was subjected to translation into regional language to be used by the students of government school. Then a pilot study on 10 students from private schools (English version of the checklist) and 10 students from government schools (Tamil version of the checklist) was carried out.

\section{Reliability}

Three measures of reliability namely Spearman-Brown, Guttman and Cronbach's alpha were given to test the reliability of the check list to assess the stress level of school students. The reliability was found to be between 0.74 and 0.83 , hence the tool was found to be fairly reliable.

\section{Conduct of the study}

Rapport with the administrators and teachers of all the participant school was established. The data with reference to the school children - 1817 of all the selected six schools were collected. No time frame for the completion of the inventory was given. However the students were encouraged to work continuously and complete the inventory as quickly as possible.

\section{Analysis of data}

The acquired data was statistically analyzed. Univariate Anova was used to compare the means of the variables namely the type of school and the gender with the stress score and again the type of school and gender with the stress trigger score and analyze the variables' effect on the stress level and its triggers of the selected early adolescents

\section{Results}

\section{A. General profile}

Out of the total 1817 respondents, the boys had the highest representation of about 55.7 per cent compared to their counterpart registering 44.3 per cent.

\section{B. Effect of the type of school and gender on the stress score}

In order to contribute to the research literature by exploring the interactive relationship of the stress score of the selected respondents among the gender and the type of school, Univariate ANOVA was carried out and the results were presented in Table 1.

Boys responding to the survey reported higher mean score on stress (a total mean score of 43.17) than the girls with a mean score of 38.47 , who responded to the survey. The results of the Anova (' $\mathrm{f}$ ' value $=78.257$, df-1, $\mathrm{p}<.01$ ) suggest that the boys reported stress levels that were significantly higher than their girl counterparts.

Whilst, considering the type of school for analysis an overall mean score of only 39 was obtained by private school students against 45.43 of government school students, which authentically proves that the type of school do influence the stress level of students. Also the ' $f$ ' value of 133.995, df-1, $p$ $<.01$ substantiates that the students enrolled in government schools were more stressed than private school students. 
Table 1. Stress score of the adolescents in relation to the type of school and gender

\begin{tabular}{|c|c|c|c|c|c|c|c|c|c|c|c|c|c|c|}
\hline & \multicolumn{6}{|c|}{ Stress level } & \multirow{2}{*}{\multicolumn{3}{|c|}{ Total }} & \multirow{2}{*}{\multicolumn{4}{|c|}{ Analysis of variance }} \\
\hline & & \multicolumn{3}{|c|}{ Private } & \multicolumn{3}{|c|}{ Government } & & & & & & & \\
\hline & & Mean & S.D & No. & Mean & S.D & No. & Mean & S.D & No. & $\begin{array}{l}\text { Sum of } \\
\text { squares }\end{array}$ & df & $\begin{array}{l}\text { Mean } \\
\text { square }\end{array}$ & 'f' value \\
\hline \multirow{7}{*}{$\begin{array}{l}\text { Student } \\
\text { Gender }\end{array}$} & Boys & 42.01 & 12.38 & 691 & 45.67 & 9.95 & 321 & 43.17 & 11.78 & 1012 & \multirow{3}{*}{$\begin{array}{l}9905.81 \\
5\end{array}$} & \multirow{3}{*}{1} & \multirow{3}{*}{9905.815} & \multirow{3}{*}{$\begin{array}{c}78.257^{*} \\
*\end{array}$} \\
\hline & Girls & 35.12 & 11.08 & 536 & 45.15 & 9.92 & 269 & 38.47 & 11.70 & 805 & & & & \\
\hline & Total & 39.00 & 12.31 & 1227 & 45.43 & 9.93 & 590 & 41.09 & 11.97 & 1817 & & & & \\
\hline & & \multicolumn{9}{|c|}{ Sum of squares -16961.137} & \multirow{3}{*}{\multicolumn{4}{|c|}{$\begin{array}{c}\text { Interaction } \\
\text { Gender vs. school }\end{array}$}} \\
\hline & & \multicolumn{9}{|c|}{$\mathrm{df}-1$} & & & & \\
\hline & & \multicolumn{9}{|c|}{ Mean square - 16961.137} & & & & \\
\hline & & \multicolumn{9}{|c|}{ 'f'-value $-133.995^{* *}$} & $\begin{array}{c}3999.54 \\
2\end{array}$ & 1 & 3999.542 & $\begin{array}{c}31.597 * \\
*\end{array}$ \\
\hline
\end{tabular}

Table 2. Effect of the type of school and gender on stress triggers

\begin{tabular}{|c|c|c|c|c|c|c|}
\hline \multirow{2}{*}{ Stress triggers } & \multirow{2}{*}{ Analysis of variance } & \multicolumn{2}{|c|}{ Type of school } & \multicolumn{2}{|c|}{ Gender } & \multirow{2}{*}{$\begin{array}{l}\text { Interaction Gender } \\
\text { vs. school }\end{array}$} \\
\hline & & Private & Government & Boys & Girls & \\
\hline \multirow{4}{*}{ Teacher } & Mean score & 7.44 & 8.01 & 7.72 & 7.51 & \\
\hline & Sum of squares & \multicolumn{2}{|c|}{131.717} & \multicolumn{2}{|c|}{19.644} & 0.00108 \\
\hline & $d f$ & \multicolumn{2}{|c|}{1} & \multicolumn{2}{|c|}{1} & 1 \\
\hline & 'f'value & \multicolumn{2}{|c|}{$22.192 * *$} & \multicolumn{2}{|c|}{$3.310^{\mathrm{NS}}$} & $0.000^{\mathrm{NS}}$ \\
\hline \multirow{4}{*}{ Money } & Mean score & 3.79 & 4.92 & 4.65 & 3.54 & \\
\hline & Sum of squares & \multicolumn{2}{|c|}{527.944} & \multicolumn{2}{|c|}{546.582} & 86.667 \\
\hline & $d f$ & \multicolumn{2}{|c|}{1} & \multicolumn{2}{|c|}{1} & 1 \\
\hline & 'f'value & \multicolumn{2}{|c|}{$168.105^{* *}$} & \multicolumn{2}{|c|}{$174.040^{* *}$} & $27.596^{* *}$ \\
\hline \multirow{4}{*}{ Attitudes and feelings } & Mean score & 5.96 & 7.00 & 6.62 & 5.89 & \\
\hline & Sum of squares & \multicolumn{2}{|c|}{439.819} & \multicolumn{2}{|c|}{237.220} & 106.637 \\
\hline & $d f$ & \multicolumn{2}{|c|}{1} & \multicolumn{2}{|c|}{1} & 1 \\
\hline & 'f'value & \multicolumn{2}{|c|}{$79.607 * *$} & \multicolumn{2}{|c|}{$42.936^{* *}$} & $19.301 * *$ \\
\hline \multirow{4}{*}{ School work } & Mean score & 6.59 & 7.71 & 7.30 & 6.52 & \\
\hline & Sum of squares & \multicolumn{2}{|c|}{512.029} & \multicolumn{2}{|c|}{275.836} & 226.982 \\
\hline & $d f$ & \multicolumn{2}{|c|}{1} & \multicolumn{2}{|c|}{1} & 1 \\
\hline & 'f'value & & & & & $36.614 * *$ \\
\hline & Mean score & 6.47 & 7.06 & 6.74 & 6.56 & \\
\hline Бxom & Sum of squares & & & & & 67.313 \\
\hline LAdinis & $d f$ & & & & & 1 \\
\hline & 'f'value & & & & & $11.953^{* *}$ \\
\hline & Mean score & 5.24 & 6.09 & 5.89 & 5.04 & \\
\hline & Sum of squares & & & & & 78.148 \\
\hline 1 (atins & $d f$ & & & & & 1 \\
\hline & 'f'value & & & & & $17.447 * *$ \\
\hline & Mean score & 3.50 & 4.64 & 4.24 & 3.40 & \\
\hline Find & Sum of squares & & & & & 131.389 \\
\hline 11 & $d f$ & & & & & 1 \\
\hline & 'f'value & & $5 * *$ & & & $42.556^{* *}$ \\
\hline
\end{tabular}




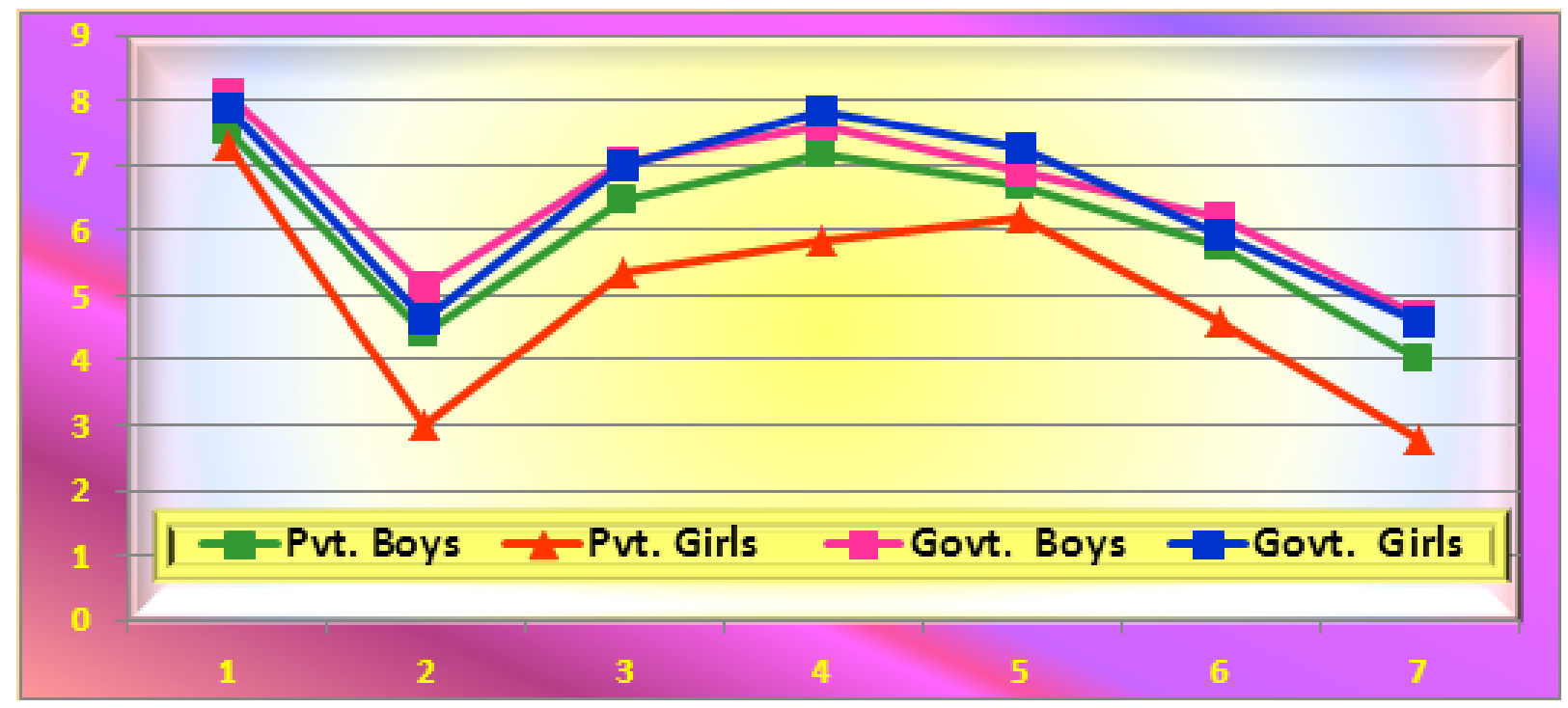

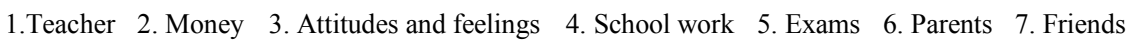

Figure 1. Institution and gender specific comparison of stress triggers mean score

\section{Effect of the type of school and gender on the stress triggers}

The descriptive statistics of the Univariate ANOVA carried out to find main effects namely the type of school on the stress triggers; the influence of gender on the same; its interaction effect has been depicted in the Table 2. The Figure 1 also chronicles illustratively the mean scores obtained by private boys, private girls, government boys and government girls with reference to their identified seven stressors.

The table shows that except for the trigger - teacher, all other six identified riggers has got a significant interaction effect between the type of the school and gender of the selected adolescents.

\section{Discusssion}

\section{A. General profile}

This unequal sex-wise distribution of the sample shows the reality of Indian scenario that more of boys in comparison to the girls were enrolled for school education. The ratio of enrolment of boys to girls in total was approximately $3: 2$. However the enrolment rate in private school (irrespective of the gender) was double the rate of enrolment in government school, which clearly depicts that the government school has been losing its charm as the days roll on. One feature that has to be noted was that more of girls $(45.6 \%)$ were enrolled in government school when compared to the percentage of enrolment in private school (43.7\%), which also brings out the verity that the parents do still focus on expensive education for boys more than girls.

\section{B. Effect of the type of school and gender on the stress score}

The purpose of this research is to verify the result of previous researches that concluded that the girls experience more stress compared to the boys. Gadzella and Baloglu [14] found that female students experience stress during changes in their life. Rai and Sinha [15] found that there is a significant difference between the stress experienced by male and female students and the research by Mates and Alison [16] showed that female students experience more stress when faced with problems compared to the male students.

The results of mean, standard deviation, ' $f$ ' value and its significance with reference to the stress score and its interaction between the gender and the type of school presents a finding in contradiction to the reports in the literature that the girls experience higher stress than do their counterparts. Though it was very clear from the present finding that the boys were subjected to higher stress than girls, the stress among the girls cannot be ignored. It should be carefully monitored.

Consequently, the magnitude of stress among middle school students was found to be high particularly among the government school students. The present finding was in accordance to the study conducted by Hussain, Kumar and Hussain [17] among 100 Delhi high school students. Similar result was obtained by Bohannon [18], who investigated the impact of stress on school children and found that the public school students were more stressed. Augustine et al [19] also has observed that the school-wise comparisons showed that the government school students had statistically higher mean scores on stress perception. The trend may be generally because the students at the government school belong to poor income group where parents' were under employed and usually take lesser interest to resolve the stress in their children. The family compulsion and burden prevent them from helping their children. On the other hand, the children of private schools mostly belong to middle income or high income group. In such families the parents take more interest 
to help and support their children to overcome stress in every way possible. Further at the school level the teachers in private schools were observed to interact better with their students than the teachers of government schools. With better atmosphere at home and more responsive school environment, the children at private schools undergo lesser stress.

Drilling further into the analysis a mean score of 42.01 (private) and 45.67 (government) were registered by boy participants against 35.12 (private) and 45.15 (government) of girl participants. In other words the boys of both the government and private school reported more or less comparable mean stress score, whereas the girls of the government school manifested higher stress score when compared to the private school girls. It was also brought into being that the lower stress level of girls in total was essentially attributable to the lower mean score of the private girls. In addition the girls and boys of government school had reported more or less equal level of stress authenticated by the mean scores of 45.15 and 45.67 respectively.

Therefore, it can be concluded that the girls in the private schools were been taken care of in all aspects by their parents in particular and the society in general, but the government school girls do not enjoy this benefit. Simple observation and informal chatting of the respondents with the investigator had revealed that the parents of female students enrolled in private school were more protective and play a key role in taking care of them in every arena of their personal and school life. Hence this dependence allows the girls to report only lower to moderate level of stress. The extra parental care of private school girls should have provided them more opportunities to share their stress with their parents.

To conclude, the interaction between gender and the type of school on the stress score was found to be statistically significant at one per cent level (' $f$ ' value 31.597 , df- 1 , p $<.01)$. In sum, there was an effect of the type of school on the stress level of the respondents, but for girls in a greater way. Therefore, the hypothesis numbered one stating that institution and gender specific differences do not have any effect on the stress level of the selected adolescents stands rejected.

\section{Effect of the type of school and gender on the stress triggers}

Teens must confront the challenges of developing healthy relationships with peers, meet the expectations of school and the responsibilities of the family and negotiate life in their neighbourhood. Stress when left unchecked or unmanaged can have a profound impact on an adolescent's physical and mental well-being leading to illness such as depression [20]. Understanding the role and impact of stressor was an important step in the prevention and treatment of its associated chronic diseases.

The figure vividly project that irrespective of the type of school and the gender the stress trigger - teacher has been identified as one of the stressor influencing more or less equally among all the respondents. However, the private girl students, as already discussed for their lower to moderate level of stress, their teacher stressor score also fall much below than all their other three counterparts. The ' $\mathrm{f}$ ' value of 3.310 being not significant endorse the verity that the stressor - teacher was not influenced by the gender of the respondents. In other words, the teacher factor was found to equally influence stress among the students.

Exam as a stress trigger was found to be the next factor, which has got equal intensity with all the respondents irrespective of the gender. The difference in mean scores between the genders being negligible with ' $\mathrm{f}$ ' value of 2.590 substantiated the statement. Whereas with type of school, a significant ' $f$ ' value at one percent level ('f' value -24.851 , df -1 and $\mathrm{p}<.01$ ) was observed.

Money was found to be a greater stressor for the government boys followed by government female lot. Government girls top the list on finding school work (mean score - 7.83) and exams (mean score- 7.26) as the source of stress. This was not surprising because the government girl students do have the responsibility of helping their mothers in her household chores and in addition they do care their siblings. An important observation of the graph shows that the government boys top the list in citing parents as a source of stress. Concurrently, the mean score of private girl respondents' had taken up the last position in all of the identified stressors owing to their low level of stress.

Whilst, a glance at the table portrays that each and every identified seven stressors was found to be significant between the main effects (the type of school and gender) and the stress trigger mean score. The interaction between the gender vs. type of school against all the stressors were also found to be significant at one per cent level except for the stressor - teacher. This finding once again evidently proves that teacher - a critical stress trigger was found to affect the students with the same intensity irrespective of the type of school or gender. Therefore, the hypothesis numbered two stating that institution and gender specific differences do not have any effect on the stress triggers of the selected adolescents stands rejected to all the triggers identified except the trigger - teacher.

\section{Conclusions}

Some of the key findings were

- Boys reported stress levels that were significantly higher than their girl counterparts.

- Students enrolled in government schools are more stressed than private school students. There was an effect of the type of school on the stress level of the respondents, but for girls in a greater way.

- Irrespective of the type of school and the gender the stress trigger - teacher has been identified as one of the stressor influencing more or less equally among all the respondents.

- Money was found to be a greater stressor for the government boys followed by government girls. 
Exams were identified as a stressor, which has got equal intensity with all the respondents irrespective of the type of school and gender. Government girls top the list on finding school work and exams as the source of stress.

- The mean scores of the private girl respondents' take up the last position among all the identified seven stressors owing to their low level of stress.

The findings discussed so far, when put together has meticulously demonstrated that the stress level and its triggers among the selected early adolescents in their middle school was startling and strongly influenced by the type of school and gender. The finding also gives a feeling of apprehension for the society in general and educators, researchers and policy makers in particular to initiate urgent strategies to overcome this fiery issue.

\section{Limitations and Directions for Future Research}

Even though this study had many strengths, results were tempered by a consideration of several methodological limitations.

- First, this analysis relied on self-report information. Subjects might either over-report or under-report their perceptions regarding personal variables. Some students may over-report their stress to make an excuse; whereas others may under-report stress to disguise their true feelings and create the image that they are mentally healthy. It is suggested future research be conducted using physiological measures to examine stress.

- Second, the demographics section did not have a choice for age, educational status and working status for parents and analyze the differences that may exist with this variable among the student population.

- Third, the survey did not sufficiently address environmental conditions such as home setting of the students, and the extra classes taken up them.

- Fourth, it has to be admitted that having students respond to the same questionnaire at different times during the school year may yield different results. Stress levels may be different closer to final exam time, or at the very beginning of a calendar school year. However the present study had no other options.

\section{REFERENCES}

[1] Steinberg, L and Morris, Adolescence, 4th edition, McGraw Hill, Boston: 492 - 493, (2001)

[2] ASRI 2002 XXII Annual Meeting June 6-9, 2002 Chicago,
Illinois, Title of the Course "Adapting New Technologies to Reproductive Immunology". American Journal of Reproductive Immunology, 47(6): 321-329.

[3] Eccles, J., Midgley, C., Buchanan, C., Wigfield, A., Reuman, D., and MacIver, D. (1993). Development during adolescence: The Impact of stage/environment fit on young Adolescents' Experiences in schools and families. American Psychologist, 48(2): 90-101.

[4] Elias, M. J., Zins, J. E., Weissberg, R. P., Frey, K. S., Greenberg, M. T., Haynes, N. M.(1997). Promoting social and emotional learning: Guidelines for educators. Alexandria, VA: Association for Supervision and Curriculum Development. Pp. 188-192

[5] DeNoon D.J. (2002).Your Child and Anxiety: School Stress Starts Early, Reviewed by Amal Chakraburtty, MD, Retrieved

athttp://www.webmd.com/anxiety-panic/features/school-stre ss-anxiety-children.

[6] Rubin, K.H., Chen, X., and Hymel, S. (1993).Socio emotional characteristics of withdrawn and aggressive children. Merrill-Palmer Quarterly, 39: 518-534.

[7] Bullock, J. (2002). Bullying, Childhood Education, 78(3): 30-133.

[8] Dacey, J. S., and Fiore, L. B. (2000).Your anxious child. San Francisco: Jossey-Bass, Pp.59-72.

[9] Stansbury, K., and Harris, M. L. (2000). Individual differences in stress reactions during a peer entry episode: Effects of age, temperament, approach behaviour, and self-perceived peer competence, Journal of Experimental Child Psychology, 76(1): 50-63.

[10] Brobeck. E, Marklund. B., and Haraldsson. K. (2007). Stress in children: How fifth-year pupils experience stress in everyday life. Scandinavian Journal of Caring Sciences, 21(3): 39.

[11] Siegelman,C.K., and Rider. E.A. (2006).Life span Human development, 5th edition, Cengage Advantage Books, India. Pp. 196-200

[12] Lopez, C., and Bhat, C. S. (2007).Supporting students with incarcerated parents in schools: A group intervention. The Journal for Specialists in Group Work, 32, Pp.139-153.

[13] Gadzella, B. M., and Baloğlu, M. (2003).High and low achieving students on processing, retaining, and retrieval of information, Journal of Instructional Psychology, 30 (2): 99-105.

[14] Rai, S., and Sinha, A.K. (2003). Transformational leadership, values, and effectiveness. Towards Creating a Context for Value Based Leadership. In Bhargava, S. (Ed.), Transformational leadership: Value-based management for Indian organizations, New Delhi: Response Books, Pp. 138-166.

[15] Mates, D., and Allison, K. R. (1992).Sources of stress and coping responses of high school students. Adolescence, 27: 461-474.

[16] Hussain. A., Kumar. A., and Hussain .A. (2008).Academic stress and adjustments among high school students, Journal of the Indian Academy of Applied Psychology, 34 (Special Issue): $70-73$. 
[17] Bohannon, A.P. (2000). The relationship of School related stressors to discipline referrals, attendance, grade point average and under achievement among high school students. Dissertation Abstracts International, 57, P. 148.

[18] Augustine, L.F., Vazir. S., Rao, S.F., Rao, V.V., Laxmaiah.A and Nair, K.M. (2011). Perceived stress, life events and coping among higher secondary students of Hyderabad, India:
A pilot study, Indian Journal of Medical Research, 134 (2): 61-68.

[19] Kessler, R. C., Berglund, P. A., Demler, O., Jin, R., \& Walters, E. E. (2005).Lifetime prevalence and age-of-onset distributions of DSM-IV disorders in the National Comorbidity Survey Replication(NCS-R).Archives of General Psychiatry, 62 (2): 593-602 